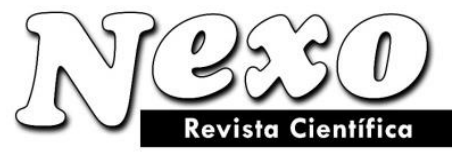

ISSN-E 1995-9516

Universidad Nacional de Ingeniería COPYRIGHT @ (UNI). TODOS LOS DERECHOS RESERVADOS

http://revistas.uni.edu.ni/index.php/Nexo https://doi.org/10.5377/nexo.v34i04.12634

Vol. 34, No. 04, pp. 1106-1119/Septiembre 2021

\title{
Estudio del perfil emprendedor de los administradores de las micro y pequeñas empresas de la región sureste de México.
}

\section{Study of the entrepreneurial profile of the administrators of the micro and small businesses in the southeast region of México.}

\author{
Patricia E. David - Miros *, María del C. David-Miros, Francisco Toto-Machucho. \\ Instituto Tecnológico Superior de San Andrés Tuxtla. División de Licenciatura en Administración. \\ San Andrés Tuxtla Veracruz. México. \\ *patriciadavid@itssat.edu.mx
}

(recibido/received: 13-marzo-2021; aceptado/accepted: 11-mayo-2021)

\begin{abstract}
RESUMEN
La ciudad de San Andrés Tuxtla, en el estado de Veracruz, se caracteriza por que la actividad comercial y de servicios la constituyen micros y pequeñas empresas lideradas por un solo individuo con dos o tres empleados. El presente trabajo, muestra los resultados de un estudio del perfil emprendedor de los administradores de las micros y pequeñas empresas en la región de San Andrés Tuxtla, Veracruz, con el propósito de establecer qué habilidades y características los han mantenido en una economía competitiva en dicho municipio. La metodología aplicada para el desarrollo del trabajo fue de tipo descriptivo-cuantitativo al realizar un diagnóstico que permitiera conocer el giro comercial de las empresas en estudio, así como la aplicación de una encuesta a 212 administradores empresariales. Entre los resultados obtenidos destacan que, de las 212 empresas estudiadas, 155 pertenecen al giro comercial y 57 al de servicios; la edad promedio de los empresarios oscila entre los 31 y 40 años; de igual manera se puede concluir que el perfil emprendedor de las micro y pequeñas empresas en la región de San Andrés Tuxtla, son personas jóvenes orgullosas con la actividad que desempeñan, creativas, con interés, capaces, persistentes, motivadas y asumidoras de riesgos. El estudio propone sugerencias para que los dirigentes adopten aspectos que puedan fortalecer las habilidades emprendedoras para la obtención de mayores resultados en su labor empresarial.
\end{abstract}

Palabras clave: Micro y pequeñas empresas, Perfil emprendedor, Habilidades, Características.

\section{ABSTRACT}

The city of San Andrés Tuxtla, in the state of Veracruz, is characterized by the fact that the commercial and service activity is made up of micro and small companies led by a single individual with two or three employees. This work shows the results of a study of the entrepreneurial profile of the administrators of micro and small companies in the region of San Andrés Tuxtla, Veracruz, with the purpose of establishing what skills and characteristics have kept them in a competitive economy in said municipality. The methodology applied for the development of the work was descriptive-exploratory and descriptivequantitative when making a diagnosis that allowed us to know the business line of the companies under 
study, as well as the application of a survey to 212 business administrators. Among the results obtained, it is worth highlighting that of the 212 companies studied, 155 belong to the commercial branch and 57 to the services sector; the average age of entrepreneurs ranges between 31 and 40 years; In the same way, it can be concluded that the entrepreneurial profile of micro and small companies in the San Andrés Tuxtla region are young people who are proud of the activity they carry out, creative, with interest, capable, persistent, motivated and risk-taking. The study proposes suggestions for leaders to adopt aspects that can strengthen entrepreneurial skills to obtain greater results in their organizational work in the business.

Keywords: Micro and small businesses, Entrepreneur profile, Skills, Characteristics.

\section{INTRODUCCIÓN}

En México existen 4, 170,755 microempresas y 94,513 pequeñas según datos de la Encuesta Nacional sobre Productividad y Competitividad de las Micro, Pequeñas y Medianas Empresas (ENAPROCE, 2018), estas constituyen principalmente el núcleo económico del país; mientras que en el estado de Veracruz hay un total de 438 mil 214 establecimientos, con 1 millón 701 mil 915 personas ocupadas en ellos. Del total de establecimientos, $96.1 \%$ son tamaño Micro y 3.8\% son Pequeñas y Medianas según el Instituto Nacional de Estadística Geografía e Informática (INEGI, 2019); y en San Andrés Tuxtla existen 3,680 unidades económicas.

Si los datos muestran que la economía mexicana es movida por Micros y Pequeñas Empresas (MyPE), tal y como lo señala (Calvo et al,1995), al afirmar que México es un país de micros y pequeñas empresas, no sólo en el ramo industrial sino en todas las actividades económicas; y que de acuerdo con la secretaría de economía, éstas representan aproximadamente el 97\% de las unidades productivas del país (Salazar y Ramírez, 2003); información que también señala la Organización para la Cooperación y el Desarrollo Económicos (OCDE, 2013), al informar que del 100\% del total de las empresas en México; el 94.4\% son micro y 4.4 son pequeñas; lo anterior da un panorama de la importancia que tienen estas empresas en el crecimiento y desarrollo de un país, región y municipio.

La importancia de las MyPE, no solo son los datos que indican el total de ellas, sino la amplia gama de giros productivos, comercializadores y servicios que ofrecen al mercado, la relación que tienen con las medianas y grandes empresas y la generación de empleos ( Regalado, 2000); además por sus ventas y número de empleados como lo menciona (Cano et al, 2017) y contribuir a la consecución de objetivos económicos y sociales que se han vuelto cada día prioridad dentro del México actual, (Mungaray et al, 2002).

De los más de 4 millones de microempresas que tiene México, las manufactureras corresponden al 13\%, $51 \%$ al comercio y $36 \%$ al sector servicios, según la ENAPROCE (INEGI, 2018). En Veracruz de las más de 400 mil del total de establecimientos del sector privado y paraestatal, $46.7 \%$ corresponden al sector comercio, $40.7 \%$ a los servicios no financieros, $10.5 \%$ a las manufacturas y $2.1 \%$ al resto de actividades económicas, Boletín de prensa (INEGI, 2019); en San Andrés Tuxtla el 52.7\% pertenece al sector comercio, $35.4 \%$ a los servicios no financieros y el 9.8 a las manufactureras.

Se podría seguir describiendo a las MyPE por la diversidad de actividades que abarca y por la consecuente contribución al desarrollo económico y social del país como lo han señalado diversos autores; sin embargo no se ha mencionado quién es el que las dirige y qué perfil debe tener para administrar a este ente económico; en este sentido (Betancur y Gallego, 2015), comenta que la gestión de la Pymes y sus resultados están influenciados por sus dirigentes y considera que conocer el perfil de los microempresarios es importante porque son ellos los que orientan el rumbo del negocio; de la misma forma (Bustamante, 2001), manifiesta que para dirigir un negocio, el microempresario debe considerar sus características personales para enfrentar 
el gran desafío de impulsar el proyecto.

En una investigación presentada por (Chávez, 2014), cuyo propósito fue identificar el perfil sociodemográfico de un microempresario o emprendedor en Huejutla de Reyes Hidalgo, así como sus características que lo llevaron a la realización de una microempresa, encontró que la mayoría se dedican al sector comercio, tienen entre 40 y 59 años, y entre las cualidades que debe poseer un empresario están las de compromiso, perseverancia e innovación.

Torres (2018), en su tesis "caracterización del microempresario en el municipio de Arauca 2017, línea de investigación desarrollo económico y calidad de vida", expone que entre los resultados más representativos el 91\% de los microempresarios pertenecen al sector comercio, son generadores de 3 o más empleos; el estudio le permitió documentar aspectos para identificar las características del microempresario entre las que destaca su perseverancia a pesar de la incertidumbre en lo financiero, y el compromiso personal para avanzar en su actividad económica generando los ingresos que le permiten conservar o mejorar la calidad de vida de él, de su familia, y de quienes se vinculan a las empresas.

Según el artículo "Análisis del perfil emprendedor: una perspectiva de género" (Fuentes y Sánchez, 2010), señalan que en las mujeres destaca la iniciativa, la creatividad y la autoconfianza como aspectos asociados al emprendimiento, en cambio, para los varones, se relaciona con características como el deseo de enfrentarse a nuevos retos o el entusiasmo ante los proyectos.

San Andrés Tuxtla, es considerado una región atractiva para el negocio; por la ubicación que tiene esta ciudad en el sureste del estado de Veracruz y al ser el centro comercial de los Tuxtlas integrada por micro y pequeños empresarios en su mayoría, con más de 20 años de vida empresarial; y debido al incremento de empresas en el municipio, como se señala en el boletín de prensa número 315/20 del 16 de julio de 2020 (INEGI; 2020), el número de establecimientos y el número de personas ocupadas sigue aumentando en los últimos años; de 2013 a 2018, los establecimientos crecieron una tasa promedio anual de 3.7 por ciento.

Por lo antes expuesto, es importante mencionar que en San Andrés Tuxtla, se han establecido por décadas microempresas cuya gestación suele responder a necesidades individuales de autoempleo, y que a menudo se encuentran en una situación de informalidad; de igual manera existen empresas cuyo desempeño responden al aprovechamiento de oportunidades de mercado a través de una eficiente e innovadora gestión empresarial; pero, ¿qué factores han hecho que sus dirigentes permanezcan en un mercado competitivo?; ¿qué características distinguen a estos empresarios?; ¿qué habilidades poseen?; ¿qué capacidades han puesto en práctica?; ¿qué perfil reúnen?. Dentro de este conjunto de factores se encuentran las de motivación, capacidad para emprender y habilidades profesionales.

Para los autores del presente trabajo, consideran que es oportuno iniciar con el vocablo emprender; esta palabra tiene varios significados, entre ellos, acometer y comenzar una obra, un negocio, un empeño, especialmente si encierran dificultad o peligro (Real academia española, 2019); de manera similar (Peralta, 2019) lo define como un tipo de trabajo diferente, sobre todo que encierra dificultad o incertidumbre; (Nieto, 2014), supone que es querer hacer algo y sentir la capacidad de poder hacerlo; es buscar y crear algo para solucionar un problema (Lázaro, 2014); sin embargo para el académico (Alcaraz, 2011 ), es un vocablo que denota un perfil, un conjunto de características que hacen actuar a una persona de una manera determinada y le permiten mostrar ciertas competencias para visualizar, definir y alcanzar objetivos; por lo que se puede observar que quien desee emprender un proyecto siempre es complicado y más si es la primera vez que lo realiza y tiene poca experiencia laboral.

En cuanto al factor motivación que debe poseer un empresario (Espada, 2002), ha escrito que desarrollar un 
trabajo con la clara convicción de que nadie sabe mejor que tú lo que tocas o vendes, es sinónimo de seguridad y un factor potente de motivación; se puede ser un excelente empresario o director de empresa, pero si no se posee un alto grado de motivación, no se consigue el éxito, los objetivos ni la felicidad.

Luego de haber expuesto el punto de vista de diversos autores se plantea la pregunta de investigación: ¿Qué características personales emprendedoras deben tener los administradores para tener éxito y dirigir las micro y pequeñas empresas de San Andrés Tuxtla?

De esta manera el documento presenta la metodología aplicada, que incluye el planteamiento del problema, los objetivos generales y específicos e hipótesis. Posteriormente se describe el tipo de investigación, se determina la población y muestra, así como la implementación de instrumentos para la recolección de datos. Finalmente, se presentan los resultados previamente analizados e interpretados para dar lugar a la conclusión la cual permitirá establecer el perfil emprendedor de los administradores de las micro y pequeñas empresas en la región de San Andrés Tuxtla, Veracruz.

\section{MATERIAL Y MÉTODOS}

\subsection{OBJETIVO GENERAL}

Conocer las características y habilidades personales de los administradores de las Micro y Pequeñas empresas, con el propósito de establecer un perfil de los emprendedores de San Andrés Tuxtla.

\subsection{OBJETIVOS ESPECIFICOS}

- Identificar el giro comercial, número de empleados y edades de los dirigentes de las empresas en estudio.

- Conocer las características y habilidades personales que poseen los administradores de las MyPE.

- Establecer el perfil emprendedor de los administradores de la micro y pequeñas empresas en la región de San Andrés Tuxtla.

- Proponer recomendaciones a los administradores de las micro y pequeñas empresas para enfrentar el desafío como empresarios.

\subsection{HIPÓTESIS}

Las características personales de los administradores de las micro y pequeñas empresas permiten definir el perfil emprendedor para dirigir las micro y pequeñas empresas de San Andrés Tuxtla.

\subsection{TIPO DE INVESTIGACIÓN}

El enfoque sobre el cual se orienta el estudio es de corte cuantitativo, el diseño es no experimental transversal debido a que por su dimensión temporal se llevó a cabo en un solo momento (Hernández, Fernández y Baptista, 2003); de campo, considerando que se realizó in situ a través de la visita a cada empresa considerada en la muestra.

En lo que respecta al alcance de la investigación, es de tipo exploratorio-descriptivo; ya que pretendió profundizar en un tema poco estudiado lo que permite relacionarnos con el fenómeno a estudiar y así obtener información sobre un contexto particular de la vida real.

Para fines de la investigación, la muestra es probabilística considerando una población de 912 MyPE, de la 
cual se determinó la muestra de estudio de 270 micro y pequeñas empresas.

\subsection{DETERMINACIÓN DE POBLACIÓN Y MUESTRA}

El estudio se llevó a cabo en San Andrés Tuxtla, en el estado de Veracruz; México; en el periodo de investigación el Instituto Nacional de Estadística Geografía e Informática (2020), en el apartado del Directorio Estadístico Nacional de Unidades Económicas reportó un total de 912 Micro y Pequeñas empresas que integraron a la población. Las actividades económicas de San Andrés Tuxtla se enfocan más en el comercio y a la prestación de servicios como el turismo. Por las características de la población fue necesario extraer una muestra de empresarios, cuyas estimaciones se calcularon con la siguiente formula (Rodríguez, 2005):

$$
\mathrm{n}=\frac{Z^{2} p q N}{N e^{2}+Z^{2} p q}
$$

Donde:

$\mathrm{n}=$ Tamaño de la muestra.

$\mathrm{N}=$ Tamaño de la población.

$\mathrm{Z}=$ Nivel de confianza.

$\mathrm{p}=$ Proporción de casos positivos.

$\mathrm{q}=$ Proporción de casos negativos.

$\mathrm{e}=$ Error.

Datos:

$\mathrm{N}=912$

$\mathrm{Z}=95 \%=1.96^{2}$

$\mathrm{p}=50 \%$

$\mathrm{q}=50 \%$

$\mathrm{e}=5 \%$

$$
\mathrm{n}=\frac{1.96^{2}(0.5)(0.5)(912)}{(912)\left(0.5^{2}\right)+\left(1.96^{2}\right)(0.5)(0.5)}=270 \text { empresarios }
$$

La muestra resultante fue de 270 micro y pequeñas empresas a las que se le aplicaron las encuestas y los resultados obtenidos se consideraron válidos para toda la población definida.

\subsection{RECOPILACIÓN DE INFORMACIÓN}

Al tratarse de un estudio cuantitativo, se eligió la encuesta como técnica de recolección de datos; el instrumento de recolección de la información fue el cuestionario; es necesario destacar que el cuestionario aplicado se sometió a una prueba piloto a 30 personas que contaban con un pequeño negocio en el municipio de San Andrés Tuxtla, con la finalidad de ajustar la comprensión y/o errores de los ítems que lo conformaron.

Dicho instrumento se estructuró en dos apartados: 1) identificación de la empresa (Giro, número de empleados, edad de los administradores o dirigentes) y 2) factores de análisis (Motivación, capacidad para 
emprender, habilidades personales y situación financiera). Cabe mencionar que se integró de 21 preguntas en donde se utilizó una escala de actitud tipo Likert de 5 niveles: Definitivamente no, Probablemente no, Indeciso, Probablemente sí y Definitivamente sí.

Para la recolección de la información, se visitaron a las 270 empresas integrantes de la muestra y se solicitó entrevista con la persona responsable de su administración o dueño. El instrumento se aplicó personalmente en algunas ocasiones y en otras se dejó para que lo respondieran; posteriormente se acudió a las empresas para recuperarlo debidamente requisitado. Del total de empresas visitadas, solo 212 lograron contestar el cuestionario.

Las respuestas obtenidas, fueron codificadas y procesadas usando la hoja de cálculo de Excel, lo que permitió obtener con valores absolutos y relativos las tablas y gráficas de resultados, a partir de las respuestas más relevantes; es decir, las que presentaron mayores frecuencias entre las opciones elegidas por quienes respondieron sobre el tema que se les preguntada.

\section{RESULTADOS}

Este apartado presenta los resultados de los factores en los que se basó el estudio sobre las características personales que poseen los administradores o dirigentes de las micro y pequeñas empresas de la ciudad de San Andrés Tuxtla, en el estado de Veracruz; durante los meses agosto- diciembre 2019; mismos que permitirán definir el perfil del emprendedor de los empresarios de estos negocios y hacer recomendaciones que permitan fortalecer la función empresarial. Cabe mencionar que el $72 \%$ de los negocios pertenecen al giro comercial y el $28 \%$ al de servicios y la edad oscila entre 31 y 40 años, con 3 empleados aproximadamente por entidad económica.

El análisis del factor motivación integrado por las frases: Me siento orgulloso(a) de lo que hago, Soy una persona creativa, Aunque no alcance mis objetivos en poco tiempo no pierdo el interés, Estoy convencido(a) de mis capacidades y sé muy bien como explotarlas, Cuando quiero algo, insisto hasta que lo consigo y Veo posibilidades creativas en cada cosa que realizo, obtuvo los resultados que se muestran en la tabla 1.

Tabla 1. Concentrado del factor motivación.

\begin{tabular}{lcccccc}
\hline \multicolumn{1}{c}{ Frase } & $\begin{array}{l}\text { Definitiva } \\
\text { mente no }\end{array}$ & $\begin{array}{l}\text { Probablem } \\
\text { ente no }\end{array}$ & Indeciso & $\begin{array}{l}\text { Probablem } \\
\text { ente si }\end{array}$ & $\begin{array}{l}\text { Definitivame } \\
\text { nte si }\end{array}$ & Total \\
\hline $\begin{array}{l}\text { Me siento orgulloso(a) de } \\
\text { lo que hago }\end{array}$ & 1 & 1 & 10 & 60 & 140 & 212 \\
$\begin{array}{l}\text { Soy una persona creativa } \\
\text { Aunque no alcance mis }\end{array}$ & 1 & 1 & 29 & 84 & 97 & 212 \\
$\begin{array}{l}\text { objetivos en poco tiempo } \\
\text { no pierdo el interés }\end{array}$ & 2 & 0 & 15 & 83 & 112 & 212 \\
$\begin{array}{l}\text { Estoy convencido(a) de } \\
\text { mis capacidades y sé muy }\end{array}$ & 3 & 2 & 17 & 94 & 96 & 212 \\
bien como explotarlas \\
$\begin{array}{l}\text { Cuando quiero algo, } \\
\text { insisto hasta que lo } \\
\text { consigo posibilidades }\end{array}$ & 4 & 2 & 22 & 94 & 90 & 212 \\
$\begin{array}{l}\text { Veo } \\
\text { creativas (de innovación) } \\
\text { en cada cosa que realizo }\end{array}$ & 9 & 2 & 26 & 84 & 91 & 212 \\
\hline
\end{tabular}

El factor capacidad para emprender se conformó por las frases: Soy capaz de adaptarme fácilmente ante 
nuevas situaciones, Veo mis problemas como un reto y no como un obstáculo, Soy persistente, Tengo la capacidad de comunicarme y mantener relaciones colaboradoras, Soy aficionado a mí trabajo y Asumo constantemente riesgos y los afronto, obtuvo los resultados que muestra la tabla 2.

Tabla 2. Concentrado del factor capacidad para emprender.

\begin{tabular}{lcccccc}
\hline \multicolumn{1}{c}{ Frase } & $\begin{array}{l}\text { Definitivam } \\
\text { ente no }\end{array}$ & $\begin{array}{l}\text { Probablem } \\
\text { ente } \\
\text { no }\end{array}$ & Indeciso & $\begin{array}{l}\text { Probable } \\
\text { mente } \\
\text { si }\end{array}$ & $\begin{array}{l}\text { Definitivame } \\
\text { nte } \\
\text { si }\end{array}$ & Total \\
$\begin{array}{l}\text { Soy capaz de adaptarme } \\
\text { fácilmente ante nuevas } \\
\text { situaciones }\end{array}$ & 2 & 0 & 17 & 84 & 109 & 212 \\
$\begin{array}{l}\text { Veo mis problemas como un } \\
\text { reto y no como un obstáculo }\end{array}$ & 0 & 1 & 17 & 97 & 97 & 212 \\
$\begin{array}{l}\text { Soy persistente } \\
\begin{array}{l}\text { Tengo la capacidad de } \\
\text { comunicarme y mantener } \\
\text { relaciones colaboradoras }\end{array}\end{array}$ & 2 & 2 & 12 & 93 & 103 & 212 \\
$\begin{array}{l}\text { Soy aficionado a mi trabajo } \\
\text { Asumo constantemente } \\
\text { riesgos y los afronto }\end{array}$ & 3 & 0 & 12 & 90 & 109 & 212 \\
\hline
\end{tabular}

Las habilidades profesionales, como otro factor de análisis, compuesta por las frases: Tengo experiencia previa y conocimientos que sostengan la actividad que realizo, Conozco el funcionamiento del sector de actividad en el que compito, Conozco el producto/servicio que estoy ofreciendo a mis clientes, Tengo interés por el sector en el que trabajo, Dedico el tiempo suficiente a mi pequeña empresa y sé dónde encontrar apoyos para mi negocio, obtuvo los resultados que muestra la tabla 3.

Tabla 3. Concentrado del factor habilidades profesionales.

\begin{tabular}{|c|c|c|c|c|c|c|}
\hline Frase & $\begin{array}{l}\text { Definitivame } \\
\text { nte no }\end{array}$ & $\begin{array}{l}\text { Probablemen } \\
\text { te } \\
\text { no }\end{array}$ & Indeciso & $\begin{array}{l}\text { Probablemen } \\
\text { te } \\
\text { si }\end{array}$ & $\begin{array}{l}\text { Definitivame } \\
\text { nte } \\
\text { si }\end{array}$ & Total \\
\hline $\begin{array}{l}\text { Tengo experiencia } \\
\text { previa y conocimientos } \\
\text { que sostengan la } \\
\text { actividad que realizo }\end{array}$ & 1 & 3 & 10 & 78 & 120 & 212 \\
\hline $\begin{array}{l}\text { Conozco el } \\
\text { funcionamiento del } \\
\text { sector de actividad en } \\
\text { el que compito }\end{array}$ & 1 & 2 & 9 & 76 & 124 & 212 \\
\hline $\begin{array}{lr}\text { Conozco } & \text { el } \\
\text { producto/servicio } & \text { que } \\
\text { estoy ofreciendo a mis } \\
\text { clientes }\end{array}$ & 1 & 0 & 3 & 60 & 148 & 212 \\
\hline $\begin{array}{l}\text { Tengo interés por el } \\
\text { sector en el que trabajo }\end{array}$ & 4 & 0 & 8 & 78 & 122 & 212 \\
\hline $\begin{array}{l}\text { Dedico el tiempo } \\
\text { suficiente a mi pequeña } \\
\text { empresa }\end{array}$ & 3 & 3 & 10 & 75 & 121 & 212 \\
\hline
\end{tabular}




\begin{tabular}{ccccccc}
\hline Frase & $\begin{array}{l}\text { Definitivame } \\
\text { nte no }\end{array}$ & $\begin{array}{l}\text { Probablemen } \\
\text { te } \\
\text { no }\end{array}$ & Indeciso & $\begin{array}{l}\text { Probablemen } \\
\text { te } \\
\text { si }\end{array}$ & $\begin{array}{l}\text { Definitivame } \\
\text { nte } \\
\text { si }\end{array}$ & Total \\
\hline $\begin{array}{l}\text { Sé dónde encontrar } \\
\text { apoyos ara mi negocio }\end{array}$ & 15 & 17 & 45 & 82 & 53 & 212 \\
\hline
\end{tabular}

En cuanto al factor situación financiera, se constituyó por las frases: Considero que los emprendedores tienen la facilidad para acceder a préstamos o créditos bancarios, Para un emprendedor es necesario contar con apoyo externo que puedan avalarlo y Considero que los emprendedores logran recuperar su inversión inicial, obtuvieron los resultados que se presentan en la tabla 4.

Tabla 4. Concentrado del factor situación financiera.

\begin{tabular}{|c|c|c|c|c|c|c|}
\hline Frase & $\begin{array}{l}\text { Definitiva } \\
\text { mente no }\end{array}$ & $\begin{array}{l}\text { Probableme } \\
\text { nte no }\end{array}$ & Indeciso & $\begin{array}{l}\text { Probablem } \\
\text { ente si }\end{array}$ & $\begin{array}{l}\text { Definitivame } \\
\text { nte si }\end{array}$ & Tota \\
\hline \begin{tabular}{lrrr} 
Considero & \multicolumn{2}{r}{ que } & los \\
emprendedores & tienen & la \\
facilidad para & acceder & a \\
préstamos o & créditos \\
bancarios & & &
\end{tabular} & 16 & 48 & 55 & 75 & 18 & 212 \\
\hline $\begin{array}{l}\text { Para un emprendedor es } \\
\text { necesario contar con apoyo } \\
\text { externo } \\
\text { amigos) } \\
\text { avalarlo }\end{array}$ & 21 & 42 & 49 & 63 & 37 & 212 \\
\hline $\begin{array}{lrr}\text { Considero } & \text { que } & \text { los } \\
\text { emprendedores } & \text { logran } \\
\text { recuperar su } & \text { inversión } \\
\text { inicial } & & \end{array}$ & 5 & 11 & 14 & 82 & 100 & 212 \\
\hline
\end{tabular}

Con base en los resultados encontrados en los instrumentos de evaluación se puede describir que el perfil de los administradores de las micro y pequeñas empresas de la ciudad de San Andrés Tuxtla poseen las siguientes características: En su mayoría son gente joven de 31 a 40 años que administran empresas comerciales y de servicio y que en promedio tienen de 2 a 3 empleados.

En lo que respecta al factor motivación, se obtuvo un alto porcentaje en las respuestas positivas, en su mayoría los administradores mantienen ese impulso que los mueve a realizar sus actividades y persisten ellas hasta lograr sus metas o fines determinados.

La capacidad para emprender es un factor muy importante para el emprendimiento de los administradores y la gran mayoría dedica tiempo y paciencia en sus actividades para llevarlas a cabo y se adaptan fácilmente a cada situación, pese a los constantes riesgos a los que se enfrentan.

Las habilidades profesionales les han permitido destacar y mantenerse en el ámbito laboral con los conocimientos específicos de cada profesión y aplicándolas correctamente en el sector en el que desarrollan sus actividades; estas habilidades de conocimiento, experiencias, interés y dedicación se van adquiriendo y mejorando con el tiempo.

Finalmente, en cuanto a la situación financiera un pequeño porcentaje de los administradores no han contado 
con un apoyo humano para avalarlos en su emprendimiento y pocos son los que están realmente informados o han contado con un apoyo financiero cuando han enfrentado una crisis o problema económico; sin embargo, pese a esto se puede concluir que logran recuperar su inversión inicial.

\section{DISCUSIÓN}

Las micro y pequeñas empresas han sido, son y serán las que muevan la economía del país, del estado y de los municipios, tal y como lo han señalado varios autores a lo largo de este trabajo; su importancia radica en los diversos sectores económicos a los que se dedica, además de la participación en el producto interno bruto y su contribución en la generación de empleos. Evidentemente, tanto en nuestro país como en el resto del mundo, son el elemento fundamental de la actividad económica, como lo demuestra su importantísima participación en términos de creación de riqueza y empleo. Su creciente importancia se ve reflejada en su papel como impulsora de la actividad empresarial, en su capacidad para emprender y en su aportación a la innovación (Soto, 2019).

Hay personas que han decidido no depender de nadie y que se limitan a ganarse la vida más o menos bien con su esfuerzo personal, lo cual tiene repercusión en el grado de bienestar que ellos alcanzan. Descubrir las características del empresario emprendedor, saber cuáles son las conductas que le han llevado a mantenerse en competencia y lograr el éxito profesional, es lo que se ha dado a conocer en el presente trabajo.

Entre los factores estudiados, se encuentra la motivación; definida como una disposición interna que activa, dirige, impulsa o mantiene un comportamiento, y hace que actuemos de una forma determinada (Gallardo et al, 2016). Las personas con alta motivación de logro encuentran más incentivos para actuar y conseguir cosas que aquellos que no tienen esta característica, de forma que ven oportunidades donde otros no ven nada o ven problemas, son pertinaces y actúan para alcanzar aquello que se proponen, es decir, tienen iniciativa (Dirube, 2012). Orientación al logro, iniciativa y confianza en uno mismo, son características de los empresarios de nuestro estudio. Como se ha mencionado en este trabajo el emprendedor es alguien que hace crecer la actividad, que crea empleo y genera riqueza, esto requiere expandir su actividad más allá de donde sus propios recursos le permiten. ¿Cómo se alcanza? otra vez parece que la motivación de logro ejerce un papel fundamental en este aspecto, pues el deseo de alcanzar metas cada vez más difíciles les hace buscar alianzas, colaboradores, socios que les permitan alcanzar sus propósitos, por lo que la motivación de logro se relaciona con la orientación al logro, la iniciativa y la búsqueda de información.

Por otra parte, la capacidad para emprender, como otro factor que tienen los empresarios se relaciona con la capacidad emprendedora; según el Instituto Nacional de Capacitación (INACAP; 2020), se define como la capacidad de actuar con iniciativa y perseverancia de modo de poder modificar la realidad siendo un agente de cambio, junto a los que lo rodean, aportando soluciones innovadoras a organizaciones productivas y sociales desde su profesión; por lo que la capacidad para emprender se debe entender como el conjunto de recursos y aptitudes que tiene una persona para desempeñar una tarea ( Fernández, 2014).

Al hablar de las habilidades profesionales, las empresas prosperan cuando se enfocan en potenciar aquellas actividades en las que tienen una ventaja competitiva, y mientras más inalcanzable sea esa ventaja, más seguro será su futuro. A nivel personal sucede lo mismo, debemos enfocarnos en potenciar nuestras habilidades y tercerizar el resto. Sabemos que debemos dedicar el tiempo a aquello en lo que somos buenos, capaces y nos apasiona, y delegar el resto (Curbelo, 2020).

Para los empresarios, conocer su situación financiera les ayudará a tomar decisiones que tengan relación con la inversión o el financiamiento (Morales y Morales, 2014); cuando se crea un negocio se invierte el 
capital para que se incremente con el paso del tiempo; por este motivo, las empresas necesitan tener una orientación, generar objetivos, así como estrategias para alcanzarlos. Las micro y pequeñas empresas actualmente tienen acceso a financiamiento y a apoyos tanto de programas a nivel federal como estatal; uno de ellos es el Programa Nacional de Financiamiento al Microempresario (Secretaría de economía, 2020), el cual busca impulsar a las y los microempresarios para que emprendan, desarrollen y consoliden sus negocios, mediante el otorgamiento de servicios de microfinanzas integrales para incrementar la productividad de sus negocios y mejorar sus condiciones de vida: en el estado de Veracruz en la página Servicios de la Dirección General de Promoción a Emprendedores y Mipymes (DGPEM) se promueve, impulsa, diseña, coordina e implementar mecanismos que contribuyan al fortalecimiento de la economía del Estado a través de esquemas que favorezcan a la competitividad y productividad para emprendedores y las micro, pequeñas y medianas empresas, brindando asesoría, capacitación, desarrollo de productos y asesoría y constitución de sociedades de responsabilidad limitada microindustrial y/o artesanal.

\section{CONCLUSIONES}

Los empresarios de las micro y pequeñas empresas en la ciudad de San Andrés Tuxtla, cumplen entre otros objetivos, contribuir al desarrollo económico y social del municipio; además de ser generadores de empleos y formar parte de la economía productiva de las medianas y grandes empresas; como toda organización constituida legalmente como persona física o moral; éstas deben ser dirigidas por personas que posean características que le faciliten aprovechar los beneficios que el entorno les provee y aprehender del medio los conocimientos, la experiencia y las habilidades que les permitan ser aún más competitivos.

El presente estudio tuvo como finalidad dar a conocer las características personales de los administradores de las Micro y Pequeñas empresas, con el propósito de establecer un perfil de los emprendedores de este municipio; dichas características se integraron en cuatro factores: motivación, capacidad para emprender, habilidades profesionales y situación financiera; en cada uno de éstos factores se cuestionaron diversas frases que permitieron inferir las habilidades que los administradores de los negocios poseen.

El factor "motivación" incluyó frases como: me siento orgulloso(a) de lo que hago, soy una persona creativa, aunque no alcance mis objetivos en poco tiempo no pierdo el interés, estoy convencido(a) de mis capacidades y sé muy bien como explotarlas, cuando quiero algo, insisto hasta que lo consigo y veo posibilidades creativas en cada cosa que realizo; los resultados de este factor mostraron que los dirigentes de las micro y pequeñas empresas son personas orgullosas, creativas, con interés, capaces, insistentes e innovadoras; ya que según la escala de actitud tipo Likert la respuesta que predominó fue la de "Definitivamente sí".

El factor "capacidad para emprender" se compuso de las frases: soy capaz de adaptarme fácilmente ante nuevas situaciones, veo mis problemas como un reto y no como un obstáculo, soy persistente, tengo la capacidad de comunicarme y mantener relaciones colaboradoras, soy aficionado a mí trabajo y asumo constantemente riesgos y los afronto; las respuestas que prevalecieron fueron "Definitivamente si" y "Probablemente sí"; por lo que se considera que los administradores de las empresas en estudio poseen la capacidad de adaptarse a los cambios, tienen la capacidad para convertir los problemas en oportunidades, son persistentes, son capaces de comunicarse, realizan las cosas con pasión y asumen riesgos.

En el factor de "Habilidades profesionales" se analizaron 6 frases: Tengo experiencia previa y conocimientos que sostengan la actividad que realizo, conozco el funcionamiento del sector de actividad en el que compito, conozco el producto/servicio que estoy ofreciendo a mis clientes, tengo interés por el sector en el que trabajo, dedico el tiempo suficiente a mi pequeña empresa y sé dónde encontrar apoyos para mi negocio; la respuesta de mayor frecuencia fue "Definitivamente si"; por lo que los empresarios son personas 
conocedoras de los productos y servicios que ofertan al mercado, poseen experiencia en la actividad que realizan, saben a dónde acudir para solicitar apoyos, y dedican tiempo al negocio que emprendieron.

La característica relacionada con la "Situación financiera" se constituyó por las frases: considero que los emprendedores tienen la facilidad para acceder a préstamos o créditos bancarios, para un emprendedor es necesario contar con apoyo externo que puedan avalarlo y considero que los emprendedores logran recuperar su inversión inicial; este factor tuvo mayores frecuencias en las respuestas "Probablemente sí " y "Definitivamente si"; por lo que se deduce que los micro y pequeños empresarios tienen acceso a préstamos y créditos bancarios, cuentan con el apoyo de amigos y familiares y recuperan su inversión inicial.

Por lo anterior es recomendable que el gobierno en sus tres niveles (Federal, Estatal y municipal) siga motivando a este sector de la economía y les permita tener un mejor acceso a la tecnología, capacitaciones, simplificación de trámites, mantener los incentivos y simplificación tributaria y apoyo financiero a través de las entidades creadas para ese fin para que sigan participando en este ambiente económico tan competido y retador.

Otro punto importante que también deben tener presente estos dirigentes es que el uso de las tecnologías ha cambiado; por lo que los empresarios deben capacitarse y entrenarse para estar a la vanguardia; por otro lago las instituciones de educación superior deberían brindar más apoyos a través de foros, encuentros, cursos, seminarios; sobre temas de emprendimiento, estrategias de comercialización y financiamiento que coadyuve en el fortalecimiento de esas capacidades y habilidades que deben tener los micro y pequeños empresarios de la ciudad de San Andrés Tuxtla, que les permita seguir compitiendo en un mercado global.

\section{BIBLIOGRAFIAS}

Alcalá Álvarez, M. del C. (2006). Sistema universitario de innovación en apoyo a la microempresa marginada de la industria de alimentos de Baja California. Baja california, México: UABC.

Anchapuri Quispe, M. y Cutipa Limachea. A. M. (2017). Perfil de empresarios exportadores MYPES de artesanía textil de Puno. Revista de Investigaciones de la Escuela de Posgrado. Vol. 6, No.3, pp. 213-220. Recuperado del sitio web: http://revistaepgunapuno.org/index.php/investigaciones/article/view/102

Betancur, C. M. y Gallego, M. (2015). Transformación organizacional: una mirada comprensiva de la gestión humana. Colombia: Universidad EAFIT.

Bustamante Peña, W. (2001). Manual de gestión de nuevos negocios para la microempresa rural. Venezuela.

Cano Mora, J. L.; Castellano Rodríguez, H.; Perroni Rocha, E. y Velasco Torres, M. (2017). El entorno económico de los negocios en México, la importancia de las PYMES en el comercio exterior. México: AMEECI.

Calvo, T., \& Méndez, B. (Eds.) (1995). Micro y pequeña empresa en México: Frente a los retos de la globalización. México: Centro de estudios mexicanos y centroamericanos. doi:10.4000/books.cemca.2646.

Cazorla Papis, L. y Cano Guillen, C. de J. (2000). El capital riesgo como instrumento de apoyo a la PYME. España: Universidad de Almería.

Chávez Meléndez, J. (2014). Aportes de administración de negocios y educación. Investigación aplicada en Tampico y Cd. Madero, Tamaulipas. México: Palibrio. 
Curbelo, F. (2020). ¿Gano o pierdo?: la mirada inversora que toda pyme debe tener. Ediciones Granica. Recuperado de https://elibro.net/es/ereader/itssat/151214?page=11

Espada García, M. (2002). Nuestro motor emocional: la motivación. Madrid, Spain: Ediciones Díaz de Santos. Recuperado de https://elibro.net/es/ereader/itssat/53027?page=30

Fuentes García, F. J. \& Sánchez Cañizares, S. M. (2010). Análisis del perfil emprendedor: una perspectiva de género. Estudios de Economía Aplicada, 28(3),1-27. [fecha de Consulta 1 de Noviembre de 2020]. ISSN: 1133-3197. Disponible en: https://www.redalyc.org/pdf/301/30120334014.pdf

Galera Cortés, E. M. (2015). Relación entre inteligencias múltiples, creatividad y rendimiento académico en matemáticas para la elección de materias optativas. España. AntropiQa 2.0

García Legazpe, F. (2008). Motivar para el aprendizaje desde la actividad orientadora: elaboración, aplicación y evaluación de un programa para la mejora de la motivación para el aprendizaje en alumnos de 1 de ESO dentro del Plan de acción tutorial: tesis doctoral. Madrid, España. Ministerio de educación.

González Bombal, I. y Villar, R. (2003). Organizaciones de la sociedad civil e incidencia en políticas públicas. Libros del zorzal.

Gray Douglas, A. y Cyr Donald, G. (1993). Cómo evaluar su potencial emprendedor. Buenos Aires, Argentina: Gránica.

Hingston, P. (2002). Inicie su negocio. Guías de negocios. Madrid, España: Pearson Educación.

INEGI (2020). Resultados definitivos de los censos económicos 2019. Boletín de prensa núm. 315/20 16 de julio de 2020, página 1/3. Recuperado de la página web: https://www.inegi.org.mx/contenidos/saladeprensa/boletines/2020/OtrTemEcon/CenEconResDef2019_Ve r.pdf

Küppers, V. (2017). Vender como cracks: Técnicas prácticas que no utilizan los merluzos. España: Plataforma

Larraz Rábanos, N. (2015). Desarrollo de las habilidades creativas y metacoginitivas en la educación secundaria obligatoria. Madrid: Dykinson.

Ludevid, M. (2009). Cómo crear su propia empresa: factores clave de gestión (2a. ed.). Barcelona, Spain: Marcombo. Recuperado de https://elibro.net/es/lc/itssat/titulos/45836.

Marriner Torney, A. (2009). Guía y dirección de enfermería. Madrid, España: Elsevier Health Sciences.

Martínez Morales, I. (2003). Condiciones de trabajo e identidad laboral en el sector hotelero de la Comunidad Valenciana: Una aproximación a las narraciones y los discursos. España: Universidad de valencia.

Morales Castro, A. y Morales Castro J. A. (2014). Planeación Financiera. México: Grupo editorial patria.

Mungaray, A. (Coord.) y Palacio, J. I. (2002). Potencial de la vinculación universitaria para una política microempresarial. México, D.F, México: Editorial Miguel Ángel Porrúa. 
Muñoz Álvarez, L. C. (2011). Habilidades requeridas para desempeñar cargos gerenciales en las pymes de la industria manufacturera sector fabricación de maquinaria y equipo n.c.p. y sus subsectores de Quito, Ecuador. Recuperado del sitio web: http://repositorio.puce.edu.ec/bitstream/handle/22000/4863/IMPRESION_10NOV2011_16_40.pdf?seque nce $=3 \&$ isAllowed $=y$

Nevarez, I. M. (2019). 8 claves para emprender proyectos innovadores: Guía de acceso a crédito y financiamiento para emprendedores. Buenos Aires, Argentina: Noveduc.

OECD. (2013). Temas y políticas clave sobre PYMEs y emprendimiento en México: OECD Publishing.

Prieto García, M. Á. (2013). Empresa e iniciativa emprendedora. Macmillan Iberia, S.A. https://elibro.net/es/ereader/itssat/42976?page $=10$

Ramírez Domínguez, J. L. y Salazar Silva, C. (2003). Regionalismo abierto: gran visión del Pacífico Mexicano. Calima, México: UCOL.

Ramírez Torres, L. C. (2018). Caracterización del microempresario en Arauca 2017. Recuperado del sitio web:https://repository.ugc.edu.co/bitstream/handle/11396/4647/Trabajo\%20Carolina\%20Ramirez.pdf?seq $\underline{\text { uence }=1 \& \text { is Allowed }=\mathrm{y}}$

Rangel Lúquez, Olivia, \& Alvarado Mejía, Marelis, \& Sierra Ortiz, Erick (2016). El perfil emprendedor como catalizador de la innovación en los jóvenes del departamento de la Guajira. Omnia, 22(3),71-86. [fecha de Consulta 1 de Noviembre de 2020]. ISSN: 1315-8856. Disponible en: https://www.redalyc.org/pdf/737/73752819006.pdf

Regalado Hernández, R. (2012). Las MIPYMES en Latinoamérica. S. 1, Argentina: B - EUMED. Recuperado de https://elibro.net/es/lc/itssat/titulos/51592.

Salinas Sánchez, J. M. (2013). Empresa e iniciativa emprendedora. Aravaca, Madrid, Spain: McGraw-Hill España. Recuperado de https://elibro.net/es/ereader/itssat/50216?page=12.

Schnarch Kirberg, A. (2010). Marketing para emprendedores. Bogotá, Colombia: Ecoe Ediciones. Recuperado de https://elibro.net/es/ereader/itssat/69144?page=18.

Sebastián Sung Park, S. y Duarte Masi, S. (2015). El perfil del emprendedor y los estudios relacionados a los emprendedores Iberoamericanos. Revista Internacional de Investigación en Ciencias Sociales. Vol. 11 n², diciembre 2015. pág. 291-314. I. Recuperado del sitio web: http://revistacientifica.uaa.edu.py/index.php/riics/article/view/271/239

Statista (2020). Ranking de países con mayor producto interior bruto (PIB) estimado de 2019 a 2024. Recuperado en la página web: https://es.statista.com/estadisticas/600234/ranking-de-paises-con-elproducto-interior-bruto-pib-mas-alto-en/

Soto Figueroa, M. (2019). Familia empresaria. Ciudad de México: Instituto Mexicano de Contadores Públicos. 


\title{
DIRECCIONES ELECTRÓNICAS
}

\author{
https://www.inegi.org.mx/contenidos/programas/enaproce/2018/doc/ENAPROCE2018Pres.pdf \\ https://www.inegi.org.mx/app/buscador/default.html?q=veracruz\#tabMCcollapse-Indicadores \\ https://siem.economia.gob.mx/ui/pubconsultaestablecimientos \\ https://www.gob.mx/pronafim \\ http://www.veracruz.gob.mx/desarrolloeconomico/ \\ https://imco.org.mx/las-mayores-economias-del-mundo-en-2017-via-banco-mundial/ \\ https://www.inegi.org.mx/
}

\section{SEMBLANZA DE LOS AUTORES}

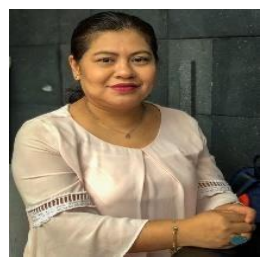

Patricia E. David - Miros: Obtuvo el grado de Licenciada en Administración de Empresas en la Universidad Veracruzana México, Desarrolló sus estudios de Maestría en el Instituto de Investigaciones de las ciencias Administrativas de la Universidad Veracruzana. Se desempeña como docente de tiempo completo en el Instituto Tecnológico Superior de san Andrés Tuxtla, en la División de Licenciatura en Administración, es profesor con perfil deseable. Trabaja en dos líneas de investigación la primera denominada Administración del Desarrollo Empresarial y la segunda Desarrollo de soluciones basadas en tecnologías emergentes. Es integrante del cuerpo

académico Ingeniería Administrativa aplicada a proyectos empresariales.

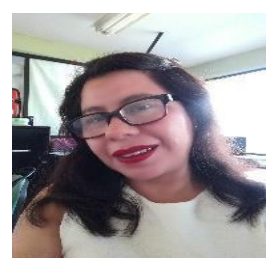

María del C. David-Miros: Obtuvo el grado de Licenciada en Administración de Empresas, y la Maestría en Ciencias Administrativas por parte de la Universidad Veracruzana en Veracruz, México, actualmente se desempeña como profesora con perfil deseable para la carrera de Licenciatura en Administración, en el Instituto Tecnológico Superior de San Andrés Tuxtla, en donde participa en líneas de Investigación Administración del Desarrollo Empresarial; Planeación Empresarial Calidad y Competitividad, es integrante del cuerpo académico Ingeniería Administrativa Aplicada a Proyectos Empresariales,

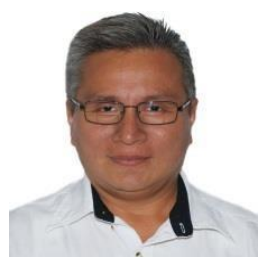

Francisco Toto-Machucho: Obtuvo el grado de Licenciado en Contaduría en el Instituto Tecnológico de Tuxtepec, México; actualmente labora en el Instituto Tecnológico Superior de San Andrés Tuxtla, en la División de Licenciatura en Administración; estudió la maestría en Ciencias Administrativas en la Universidad Veracruzana, México y la especialidad en Competencias Docentes en la Universidad Pedagógica Nacional, México; es líder del cuerpo académico Ingeniería Administrativa Aplicada a Proyectos Empresariales y trabaja en la línea de investigación Administración del Desarrollo Empresarial. 